\title{
Simulation Modelling in the Sizing of City Logistics Systems - a Study for Concentrated Delivery Points
}

\author{
K. BÓNA ${ }^{1}$, D. L. SÁRDI ${ }^{2}$ \\ ${ }^{1}$ Budapest University of Technology and Economics, Department of Material Handling and Logistics Systems, \\ krisztian.bona@logisztika.bme.hu \\ ${ }^{2}$ Budapest University of Technology and Economics, Department of Material Handling and Logistics Systems, \\ david.sardi@logisztika.bme.hu
}

Abstract. Nowadays, urban freight traffic is causing significant noise and air pollution, so it is in the focus of green logistics developments, both in technology and system organization. Based on experiences within city logistics, significant problems are caused by the so-called concentrated sets of delivery points, where there are several delivery points with heavy freight traffic in a relatively small area. Since the summer of 2015, we collected lots of data about stores of these delivery points to support the modelling and the simulation of the new green solutions for the examined city logistics systems. Based on our results we can say, there are significant savings in these systems, so it is worth to deal with developing new, gateway-concept-based and consolidation-based solutions.

\section{Introduction}

In the viewpoint of our project, there are two main groups of delivery points. There are single delivery points and the concentrated sets of delivery points, they include more single delivery points according to some aspects.

Concentrated sets of delivery points have two main groups: there are sets organized by opened or closed infrastructure. Closed infrastructure means that the concentrated set is marked by a building (like in the case of shopping malls, hypermarkets, markets of duty-free areas of airports). In the case of opened infrastructure there is no building, so the concentrated set of delivery points is bound by roads or by a square (like a shopping area or an outdoor market).

Based on the data of Hungarian Central Statistical Office in Budapest there are approximately 30.000 retailers [1]. We can find also 41 shopping malls in the city with approximately 4.000 stores, so more than $10 \%$ of all retailers can be found in these concentrated sets of delivery points and there are also several markets, hypermarkets and a shopping area with several shops in the city. On figure 1, we can see the concentrated sets of delivery points of Budapest (orange: shopping malls, blue: hypermarkets, green: markets, purple: shopping area, red: airport).

According to our earlier assumptions, these concentrated sets of delivery points are causing significant traffic flows, and also noise and air pollution; while their logistics systems are badly constructed there is no innovative technology used, and their processes are not handled by a city logistics provider in a common system. There are several gateway-concept based city logistics systems around Europe, 
where they use consolidation. In these systems, the providers are operating mostly with green road vehicles (for example electric ones), but in some cases there are other green vehicles too, like in Amsterdam (where DHL operates with cargo ships and cargo bikes too) or Zürich (where they use cargo trams in the waste management system of the city).

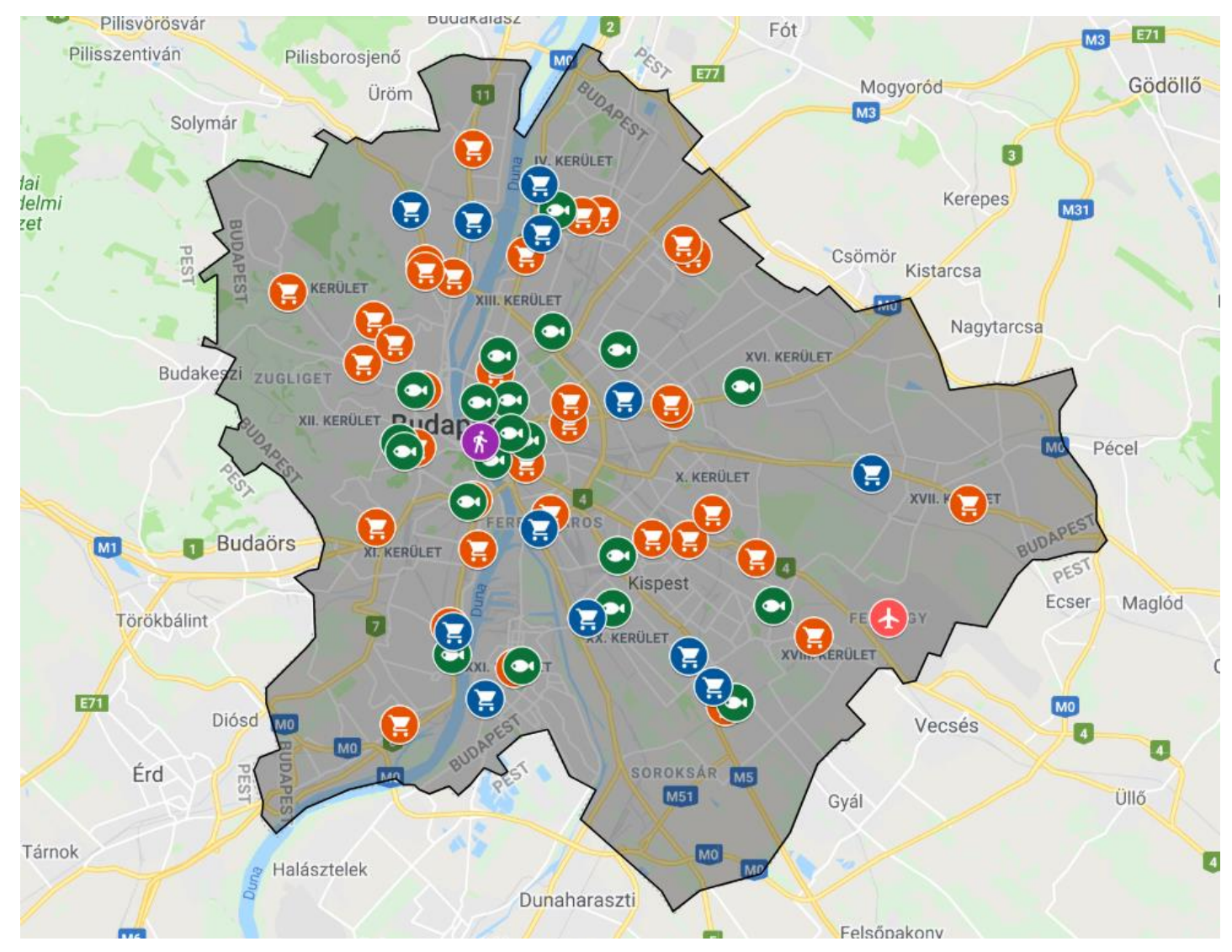

Figure 1. Concentrated sets of delivery points in Budapest on Google Maps

Some European projects (for example in Bristol or Padova) [2] show us that the innovative multistage city logistics systems can reduce performances and emissions significantly in the delivery systems of concentrated sets of urban delivery points (mostly in case of urban shopping areas). In case of Bristol (where in the Broadmead Freight Consolidation Scheme system they deliver goods to more than 60 shops of a shopping area in the city center, and the consolidation center can be found at the city border), where they deliver to 63 stores in a two-stage system, they reduced mileage by $196.000 \mathrm{~km}$ and $\mathrm{CO}_{2}$ emissions by 22,5 t between 2006 and 2009 [3].

Based on the success of consolidated city logistics systems in other cities, in 2015 we started to examine the city logistics systems or concentrated sets of delivery points in Budapest. First, we collected data about them which we used later for simulation and mathematical modelling of the cost structure and the physical processes. 


\section{Data collection}

When we started our research project, we had to realize there is no available data about the current logistics systems of concentrated sets of delivery points in Budapest, so at the one we couldn't evaluate the current operation and we didn't have data for simulation modelling. Because of this, in 2015 we developed a research methodology which makes it possible to examine the city logistics characteristics of concentrated sets of delivery points in a standard way. It has two parts: an exploratory research and a questionnaire with questions about all important logistics fields which must be filled in by the shops in the examined area [4]. In the exploratory research, there are three main components: a field study, an expert interview with several given questions about logistics operation and the examination of relevant bylaws (the house rule of the area and the road traffic rules of the surroundings). The questionnaire contains several questions about every important logistics field. There are questions about general parameters, supply parameters, home deliveries, deliveries between shops, storage parameters, IT system and about willingness of participation in new logistics systems.

By using this methodology, we examined 3 shopping malls and a shopping area in the city center of Budapest and collected data of nearly 500 shops inside them. In the next years we would like to collect more data about other concentrated sets of delivery points that have other characteristics, like a market, a shopping mall in external districts of the city or a shopping area in a smaller city.

The collected data shows us that the expected problems are real, they deliver with high frequency (for example in case of shopping malls, the shops have daily average 0,7 deliveries, which would mean daily 2800 deliveries only for the 4000 stores they are in malls in Budapest), mostly in smaller lorries. It is also a problem as they deliver in the rush hour (which has negative effect on the urban road traffic and also makes difficulties for the customers of the stores because of the material handling processes in the customer area) instead of night deliveries and they deliver mostly only small (non-standard sized) packages to the shops of the concentrated sets of delivery points instead of standard pallets of containers. Because of these problems we started to develop new, consolidation-based system concepts for the city logistics systems of concentrated sets of delivery points.

\section{Modelling on mesoscopic level}

First, we modelled only the supply processes, then we developed the mathematical model of the cost structure and finally we added the home deliveries and the inverse logistics processes. For the simulation runs, we used data from 178 stores from shopping malls after developing the simulation model in MS Excel and the mathematical model of the physical processes.

\subsection{Mathematical and simulation model of logistics processes}

In this project, we modelled and examined the current logistics system and a future two-stage system, where we inserted a consolidation center between the suppliers and the concentrated sets of delivery points and converted the logistics areas of the malls into cross docks. In the modelled new system which is like the earlier mentioned solutions, a city logistics provider operates the deliveries. The main 
purpose of the simulations was to compare performances and emissions (of the supplies and the inverse transactions) in the current and in the new system; so first, we only modelled the physical processes [5]. The mathematical model we developed models all the physical processes, so here we can only present the most important components of it.

The first component of the model examines the operation of the current system, the second works with the new system. The components are similar: first, they generate when we need to deliver and generate the amount of goods (in weight and in volume) to be delivered and the distance to be covered. Below, you can see the mathematical supply generator of the current system, this is the base of the model. The first formula shows us if we have the type "i" delivery transaction on day "j" or not, where $N_{i}^{\text {sup_day }}$ means the monthly maximum number of delivery days, $r_{i, j}$ is a random number between 0 and 1 with uniform distribution and $q_{i}$ is a calculated probability value. Second formula shows us, do we have the given delivery transaction in hour "l" on day "j" or not, where $R_{i, j}^{l}$ is a random number between 0 and 1 with uniform distribution and $Q_{i}$ is another probability value. Supply generator works similarly in case of the new system too.

$$
\begin{gathered}
x_{i, j}=\left\{\begin{array}{c}
0, \text { if } \sum_{k=1}^{j-1} x_{i, k}=N_{i}^{\text {sup_day }} \\
0, \text { if } x_{i, j}-1=1 \text { and } N_{i}^{\text {sup_day }}<7 \\
0, \text { if } \sum_{k=1}^{j-1} x_{i, k}<N_{i}^{\text {sup_day }} \text { és } r_{i, j} \geq q_{i} \\
1, \text { if } \sum_{k=1}^{j-1} x_{i, k}<N_{i}^{\text {sup_day }} \text { és } r_{i, j}<q_{i}
\end{array}\right\} \\
x_{i, j}=1 \\
T W_{i}^{S M(U L)} \leq k \\
T W_{i}^{S M(L L)} \geq k \\
\sum_{k=1}^{l-1} x_{i, j}^{k}<N_{i}^{\max (\text { day })} \\
1, \text { if }\left\{\begin{array}{c}
\max (\text { month }) \\
R_{i, j}^{l}<Q_{i} \\
0, \text { else }
\end{array}\right\}
\end{gathered}
$$

As an example, the supply generator worksheet of the simulation model of the current system can be seen in Figure 2. 


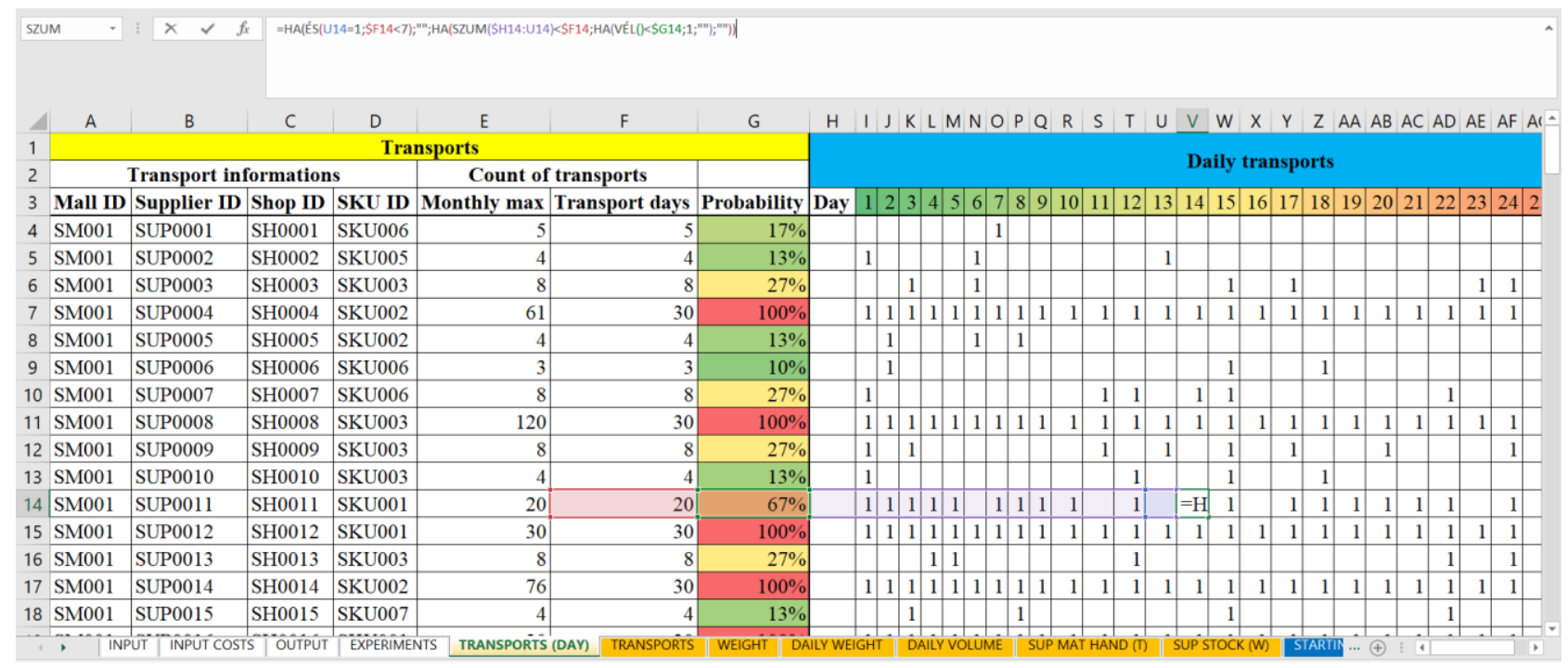

Figure 2. Supply generator worksheet of the MS Excel simulation model

After modelling the amounts, it generates the delivery distances. From these parameters the model calculates the delivery performance, the consumption (petrol and fuel oil) and the emissions $\left(\mathrm{CO}, \mathrm{CO}_{2}\right.$, $\mathrm{HC}, \mathrm{NO}_{\mathrm{x}}, \mathrm{PM}$ ), and it models also the stocking points of the system by use of SS (Safety Stock)-model. The opening stock of the consolidation center can be seen below. In the formula, $U_{i}{ }^{C C}$ is the safety factor according to normal distribution, $D\left(M_{i, j}^{C D P}\right)$ is the standard deviation of the delivered weights, $n_{i}^{\text {box/pal/oth }}$ is the expected value of number of boxes/pallets/others per delivery and $m_{i}^{b o x / p a l / o t h(\max )}$ is the maximum weight of given delivery units.

$$
K_{i, 0}^{C C}=U_{i}^{C C} * \sqrt{D\left(M_{i, j}^{C D P}\right)}+\left(n_{i}^{b o x} * m_{i}^{b o x(\max )}+n_{i}^{\text {pal }} * m_{i}^{\text {pal (max })}+n_{i}^{o t h} * m_{i}^{\text {oth }(\max )}\right)
$$

In the case of the new system, the model needs to calculate the number of concentrated deliveries as well (which must be handled by the city logistics provider), as you can see in the formula below, where $C^{\text {sup_CC_road }}$ means the capacity of the vehicle of the city logistics provider (in weight and in volume), $r^{\text {road }}$ is the average utilization factor and $M_{j}^{C D P}, V_{j}^{C D P}$ is the amount of goods to be delivered in weight and volume.

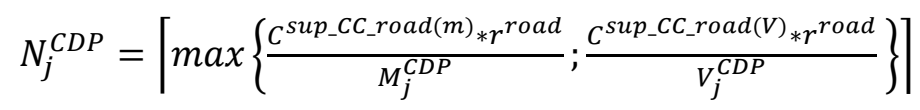

In both cases it generates the number of empties to be handled by the inverse deliveries and the home deliveries too, based on Clarke\&Wright VRP-estimation (for circular area) [6], and it calculates the performances, consumption and emissions that belong to these transactions. The model also calculates the material handling time needs in the current and also in the new system.

\subsection{Mathematical model of the cost structure}

After developing the mathematical and the simulation model of the physical processes, we also created the mathematical model of the cost structure. We needed a special cost structure which describes the 
special logistics processes we examined, and which can be fitted to the mathematical and simulation model we developed.

We modelled the logistics costs in three dimensions and could easily adopt it to the existing system architecture. The three dimensions are the cost centers (e.g. suppliers sites, consolidation center, shops), the companies of the systems (e.g. store owners, logistics providers) and the processes of the system (loading, delivery processes, storage processes, intralogistics operation and administration). The given cells of this three-dimensional matrix give as the logistics costs of the given company in the given process at the given cost center. The three-dimensional cost structure with the companies, cost centers and processes can be found in Figure 3, for the current system.

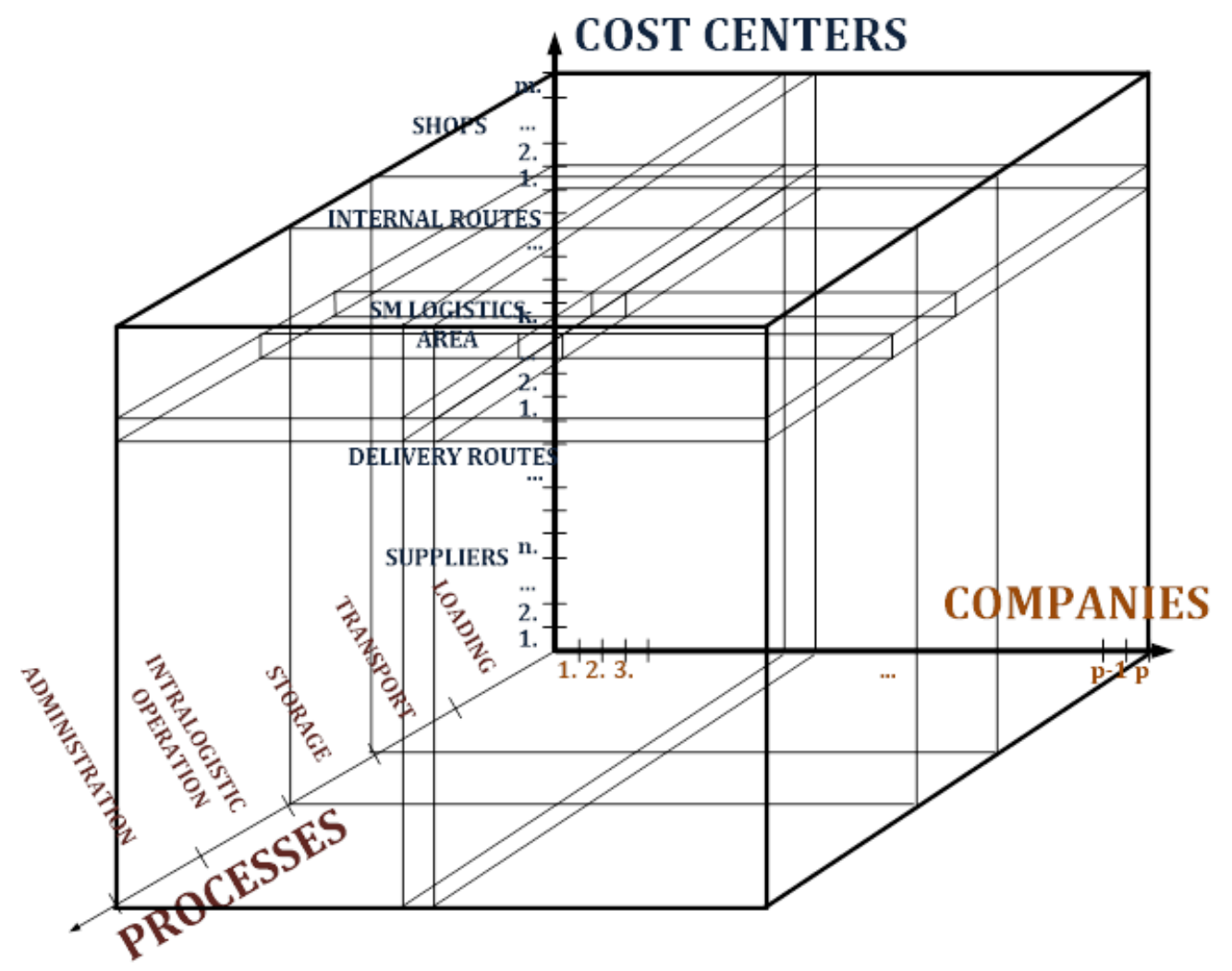

Figure 3. The cost structure of the current city logistics system of concentrated sets of delivery points

For the simulations, we collected specific cost data from former projects and tenders [7].

\section{Results of the simulation}

Before the simulations, we validated and verified the model. The simulation model worked with random generators for which parameters are calculated from the statistics of the collected data. We compared the examined systems based on the amount of goods. In the current system, we deliver $1.346,1 \mathrm{t}$ goods monthly, in the new system this is $1.356,2 \mathrm{t}$ between the suppliers and the consolidation center and 1.338,1 t between the center and concentrated sets of delivery points, so the differences are $+0,7 \%$ and $-0,6 \%$ which are relatively small and negligible. In the current system, we have 44,8 tempties and 54,1 t goods monthly for home deliveries; in the current system these are 43,9 
$\mathrm{t}$ and 47,4 $\mathrm{t}$ empties (differences are $-2,1 \%$ and $+5,7 \%$ ), and 49,8 $\mathrm{t}$ goods for home deliveries (difference is $-8 \%$ ). So we have still relatively small, but bigger differences because of the smaller amounts to be handled and the sporadic demands.

\subsection{Physical parameters of logistics processes}

Based on the results of the experiments, in the current system we have 3.397 monthly deliveries (standard deviation 16,5). In the new system, between the suppliers and the consolidation center there are 1.339 monthly merged deliveries (st. dev. 16,7), between the center and the malls there are 269 monthly consolidated deliveries (st. dev. 6). This is a significant reduction of transactions. In the current system, we have 696 monthly empties handling transaction (st. dev. 7,5), in the new system, between the suppliers and the consolidation center there are 227,3 of them per month (st. dev. 8,1). Between the center and the concentrated sets we can handle them while the vehicles are returning to the consolidation center.

The sum mileage (with empty handling) in the current system is $635.385 \mathrm{~km}$ monthly, in the new system we can reduce it to $316.109 \mathrm{~km}$ (which is more than a $50 \%$ reduction). This means also a significant reduction of consumption and emission too, for example we reduce the monthly $\mathrm{CO}_{2}$ emissions from 7,1 tons to 3,5 tons (all other emission reduction rates are similar to this).

The only parameter which is increasing (by 14\%) is the delivery performance, because of the new point in the system (the consolidation center). In the current system it is $152.852 \mathrm{tkm} / \mathrm{month}$, in the new system it is $174.983 \mathrm{tkm} / \mathrm{month}$, but in the city, we have a $38 \%$ performance reduction, because we have shorter delivery routes in the city.

In the home deliveries we need to handle monthly approximately 50 tons of goods, this means monthly 4.097 transactions in the current and 991 consolidated transactions in the new system which means a monthly approximate $3.000 \mathrm{~km}$ mileage-reduction.

You can see the comparison of physical parameters of the current and the new system on Figure 4. 
International Journal of Engineering and Management Sciences (IJEMS) Vol. 4. (2019). No. 1

DOI: 10.21791/IJEMS.2019.1.1.

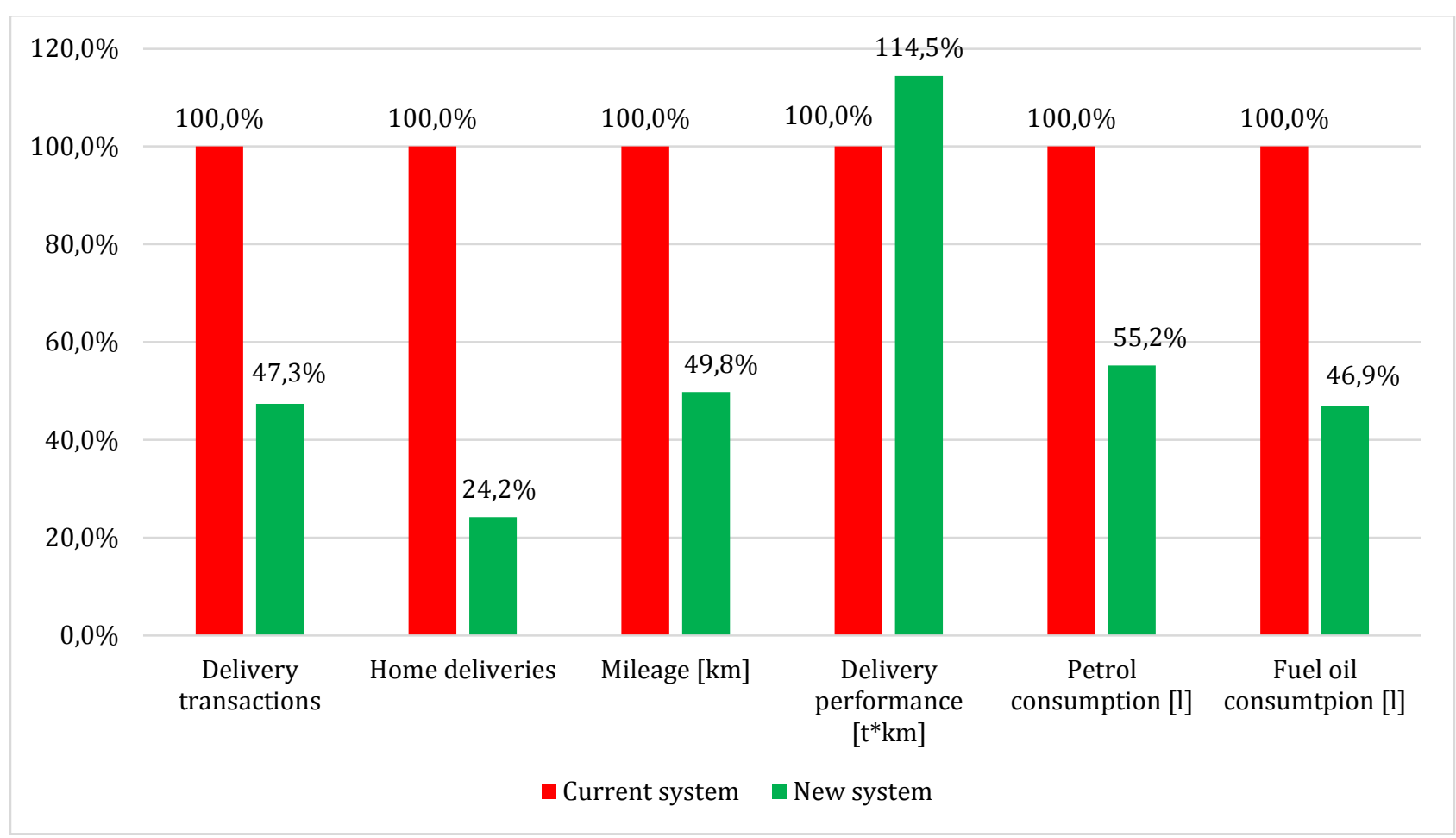

Figure 4. Comparison of the parameters of the examined city logistics systems

\subsection{Costs of logistics operation}

Based on the simulation runs, the sum of monthly logistics costs in the current system (for 178 shops) is approximately 288.000 Euros. In the new system, we can reduce it to 216.000 Euros (see on Figure 5 ) which means a cost reduction of $25 \%$, because of the significant reduction of number of delivery transactions, and with that the reduction of delivery costs. The only cost parameter which is increasing is the sum cost in the consolidation center. This is a new point in the system with monthly approximate costs of 35.000 Euro, which is less than the delivery cost reduction. The costs of supplier sites, concentrated delivery point's logistics areas, internal material handling routes and stores are similar in both system. 


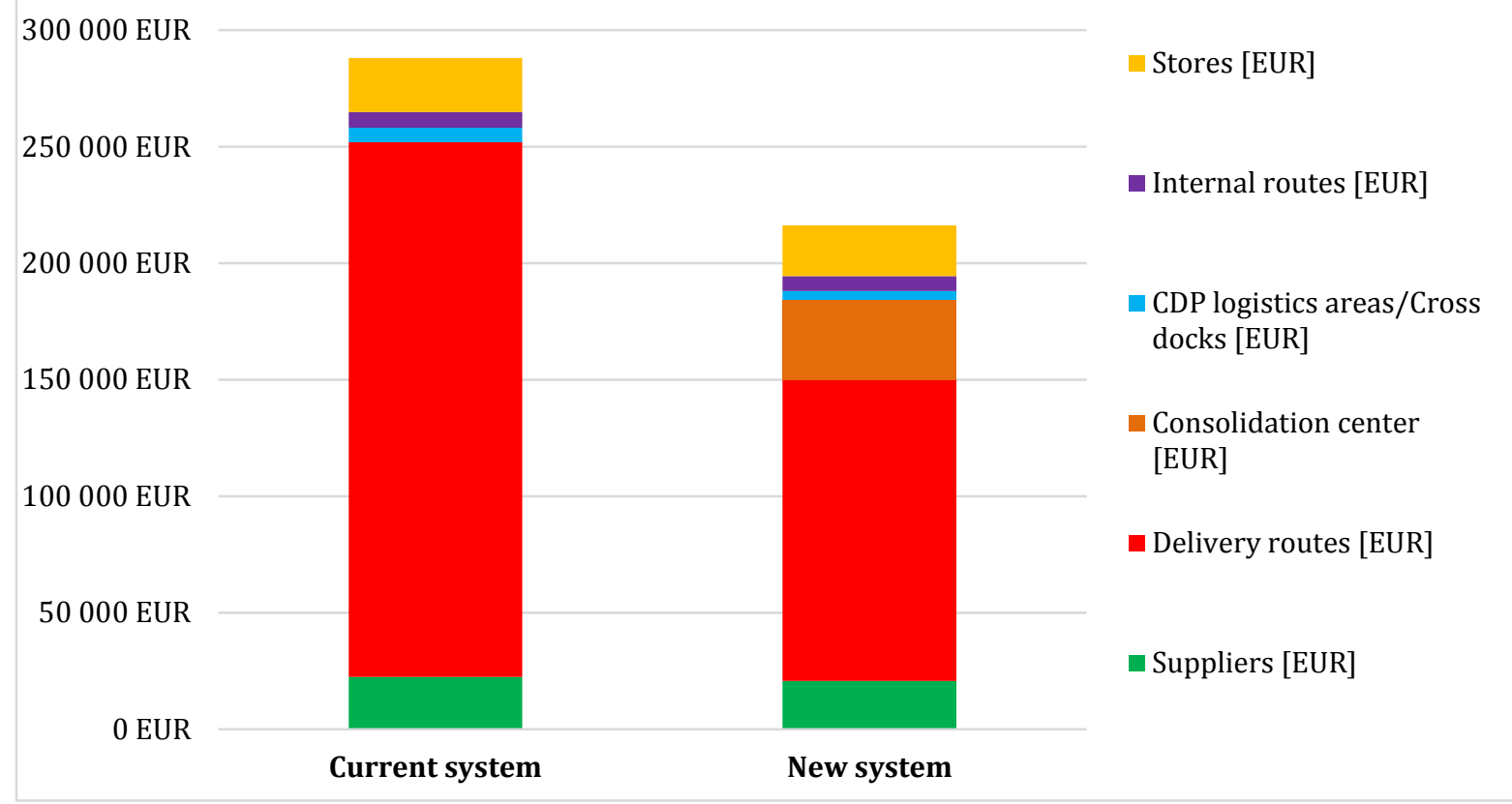

Figure 5. Comparison of monthly logistics costs

We also examined the effects of parameter changes on the sum cost. We can say that the increasing of number of deliveries and the increasing of specific delivery costs has the most significant effect on the reduction of logistics costs. You can see the savings caused by using the new system in Figure 6, in case of increasing of given parameter (or parameters) by $25 \%, 50 \%, 75 \%$ and $100 \%$.

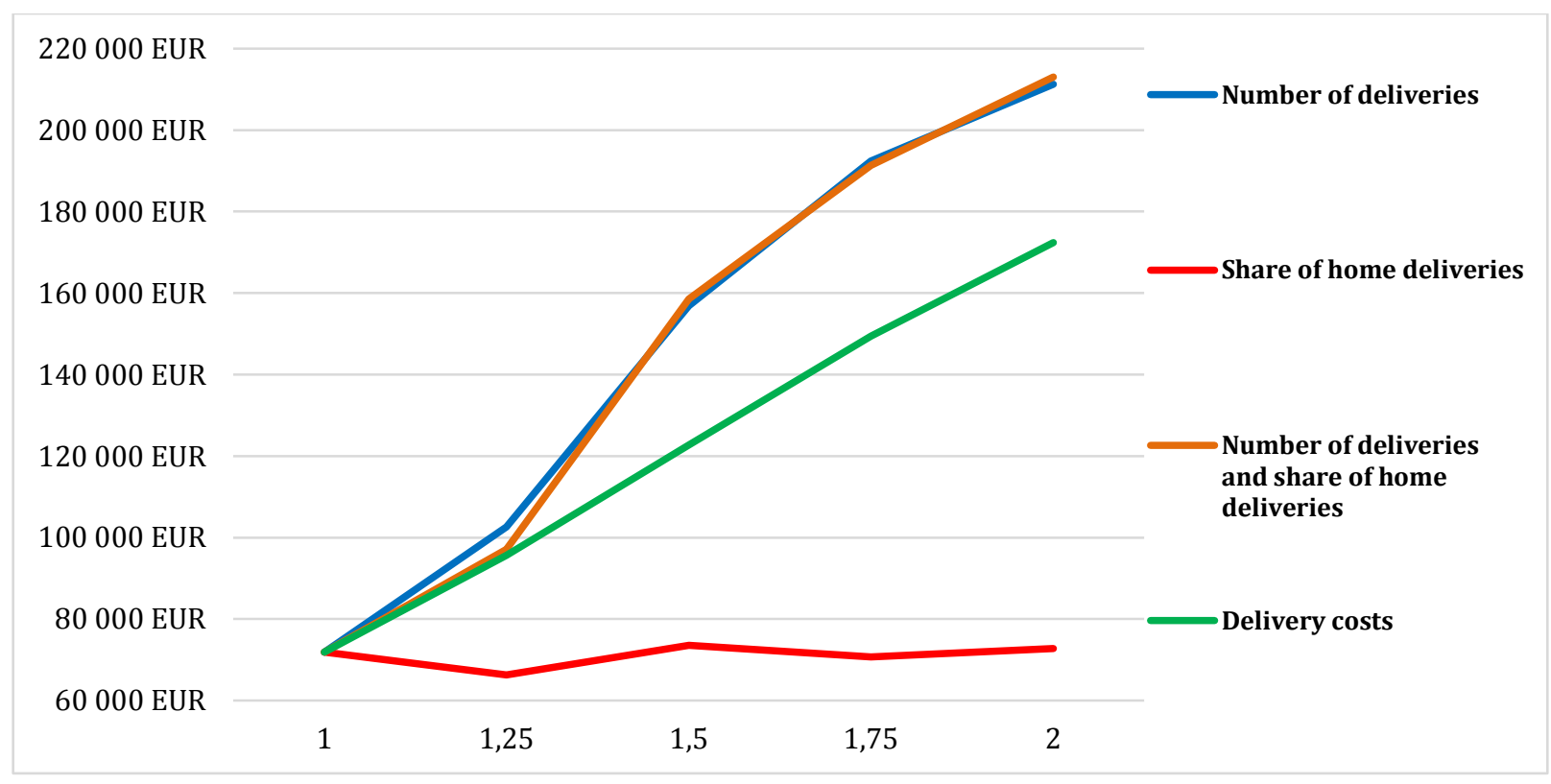

Figure 6. Cost saving in case increasing of given parameter(s)

Of course, the investment costs of the new city logistics system are not negligible, but we don't have exact data about this yet. For the new system, new infrastructure needs to be planned, we need to invest in new vehicles (maybe with some special technologies too, e.g. cargo trams or cargo boats) and 
a new IT system is also needed, but on the operational side in the case of only 178 shops we are going to have significant operation cost reduction based on our experiments (and by use of this data, later we can also examine the returns in the system). However, it can be deservedly assumed, that the use of innovative and modern technologies could even more reduce the emissions and costs.

\section{Summary}

In our paper, we presented our results about the mesoscopic level modelling of current and new city logistics systems of concentrated sets of delivery points. We started our research in 2015 without any data about these delivery points, now we have real data about nearly 500 shops of 4 concentrated delivery points and other data collection is also in progress. By use of our simulation model, we examined the current system and also a new, two-stage system with consolidation center and cross docks and based on our results, we can say that the use of this new system could cause significant performance improvement and cost reduction. In our project, we also modelled a special, three-stage new system where we use mobile storages and cargo bikes in the delivery system of shopping malls and we saw several interesting results also about this system [8]. The topological modelling of shopping areas is also in progress, this will make it possible to model also the city logistics processes of concentrated sets of delivery points with opened infrastructure too.

Now, we can say, that we can expect significant cost reduction on the operational side by use of the new, two-stage logistics system and it is worth dealing with the examination and modelling of current and future city logistics systems of concentrated sets of urban delivery points.

\section{Acknowledgment}

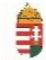

Supported BY the ÚNKP-18-2 NEW NATIONAL EXCEllenCE Program of the Ministry of Human CAPACITIES

\section{References}

[1] Hungarian Central Statistical Office (2017) A kiskereskedelmi üzletek számának alakulása. URL: http://www.ksh.hu/docs/hun/xstadat/xstadat_evkozi/e_okk012.html

[2] A. Gialos - A. Ntzoufas - V. Zeimpekis: Urban Consolidation Centers: State-of-the-art, best practices and operational challenges, ESCC 2016 Marathon-Athens. URL: https://slideplayer.com/slide/12410798

[3] T. Hapgood: Broadmead Freight Consolidation Scheme, URL: https://www.centrallondonfqp.org/app/download/12244698/Bristol+consolidation+scheme+ 230408.pdf

[4] B. Mészáros - D. L. Sárdi - K. Bóna (2017) Monitoring, measurement and statistical analysis (MMSA) based methodology for improvement city logistics of shopping malls in Budapest. World Review of Intermodal Transportation Research. 6 (4) 352-371. 
[5] D. L. Sárdi - K. Bóna (2017) Developing a mesoscopic simulation model for the examination of shopping mall freight traffic in Budapest. IEEE Smart Cities Symposium 2017, Prague, DOI: https://doi.org/10.1109/SCSP.2017.7973835

[6] F. Robuste - M. Estrada (2004) Formulas to Estimate the VRP Average Distance Traveled in Elliptic Zones. CENIT - Center for Innovation in Transport Technical University of Catalonia, URL: https://www.researchgate.net/publication/240638282_Formulas_to_Estimate_the_VRP_Averag e_Distance_Traveled_in_Elliptic_Zones

[7] K. Bóna - Á. Róka - D. L. Sárdi (2018) Mathematical Modelling of the Cost Structure of the Logistics System of Shopping Malls in Budapest. Periodica Polytechnica Transportation Engineering 46(3) 142-150. DOI: https://doi.org/10.3311/PPtr.12073

[8] D. L. Sárdi - K. Bóna (2018) Macroscopic simulation model of a multi-stage, dynamic cargo bikebased logistics system in the supply of shopping malls in Budapest. IEEE Smart Cities Symposium 2018, Prague, DOI: https://doi.org/10.1109/SCSP.2018.8402680 